\section{Edukasi Pemasaran Daring untuk Meningkatkan Pemasaran Produk UMKM Guesin Pacs Desa Cibodas Jawa Barat}

\section{Heny Wibowo', Zani Mami², Rahmadianty Anastya Suryaningrum ${ }^{3}$, Shafira Salsabila Agustami4, Gusti Ayu Dewi Pamungkas5, Nurhikmah Komala Sa'baní}

Fa kultas Ilmu Sosial dan Ilmu Politik, Universitas Pa djajdran

1hery.wibowo@unpad.ac.id, 2ziani1700 1@mail.unpad.ac.id, 3rahma dianty 1700 1@mail.unpad.ac.id, 4shafira17007@ma il.unpad.ac.id, 5gusti17001@mail.unpad .ac.id, 6nurhikmah16001@mail.unpad.a c.id

Artic le history

Received : 9 Maret 2020

Revised : 9 Juni 2020

Accepted : 9 Juni 2020

*Corresponding author email: hery.wibowo@unpad.ac.id

No. doi: https://doi.org/10.24198/sa wala.v1i2.26593

\begin{abstract}
Abstraksi
Sektor UMKM menupakan unit usaha berbasis masyarakat yang rentan dengan kerasnya persaingan usaha dan pemasaran. Maka, seluruh upaya ataupun investasi untuk membantu UMKM untuk meningkatkan kemampuan usahanya, a dalah sesua tu yang layak diperjuangkan.
\end{abstract}

Hadimya Masyarakat Ekonomi Asean dan Revolusi Industri 4.0, telah mengubah perilaku manusia dalam dunia bisnis, kewirausahaan dan secara lebih khusus aktivitas pemasaran. Maka, diperlukan kiranya sebuah tindakan khusus bagi pelaku UMKM, khususnya di pedesaan, untuk dapat bersaing secara kompetitif dalam era digital ini. Program Pengabdian Masyarakat ini bertujuan untuk membantu para pelaku UMKM meningkatkan ketera mpilan pela ku pribadi maupun kapasitas usahanya. Salah satu UMKM yang secara konsisten mempertahankan dan mengembangkan usaha berbasis potensi lokal adalah usaha kewirausahaan berbasis masyarakat yang menghasilakan produk Guesin Pacs. Adapun bahan dasar dari usaha ini adalah produk makanan berbasis telur asin. Maka, dalam rangka meningkatkan kualitas dan kapabilitas pelaku usaha untuk memasarkan produknya secara daning atau berbasis intemet tim melakukan sejumlah kegiatan. Proses pengabdian dimulai dari pengumpulan data awal melalui wawancara dan observasi untuk mengetahui lebih dalam kondisi usaha, lalu dilanjutkan dengan melakukan pelatihan dan pendampingan usaha dalam rangka meningkatkan kemampuan pelaku usa ha melakukan pemasaran secara daring

Kata Kunci: pemasaran, daring, e-commerce, Guesin Pacs, UMKM (Usaha Mikro Kecil dan Menengah)

\section{Abstract}

The MSME sector is a community-based business unit that is vulnerable to the fierce competition in business and marketing. Thus, all efforts or investments to help MSMEs to improve their business capabilities are something worth fighting for.

The presence of the Asean Economic Community and the Industrial Revolution 4.0, has changed human behavior in the world of business, entrepreneurship and more specific ally ma rketing activities. Therefore, it is necessary to have a special action for SMEs, especially in rural areas, to be able to compete competitively in this digital era. The Community Service Program aims to help MSMEs improve their personal skills and business capacity. One of the MSMEs that consistently maintains and develops business based on local potential is a community-based entrepreneurship business that produces Guesin Pacs products. The basic ingredients of this business are salted egg based food products. So, in order to improve the quality and capability of business actors to market their 
products online or intemet-based, the team carries out a number of activities. The service process starts from the initial data collection through interviews and observations to find out more about the condition of the business, then continues with conducting training and business assistance in order to improve the ability of businesses to do online marketing

Keywords: marketing, online, e-commerce, Guesin Pacs, UMKM (Micro, Small and Medium Enterprises)

\section{PENDAHULAN}

Memasuksi awal abad 21 ini, Indoensia masih sangat diwamai oleh usaha-usaha tradisional yang tak lekang oleh waktu dan tetap membutuhkan perubahan (Kasali, 2017). Selanjutnya, sebagai salah satu negara di Asean, Indonesia juga telah tergabung dalam pasar MEA (Masyarakat Ekonomi Asean), yaitu era perdagangan bebas, dimana batas antar negara tidak lagi menjadi pembatas tinggi seperti era sebelumnya (Kartajaya, 2015). Maknanya, seluruh pelaku industry akan menghadapi persaingan yang belum pemah dihadapi sebelummya

Pada era revolusi industry 4.0, lahir sejumlah era baru yang identic dengan digitalisasi dan otomatisasi, perpaduan intemet dan manufaktur (Irianto, 2017 dalam Haqqi \& Wijayanti, 2019). Dalam revolusi ini, teknologi-teknologi baru dan inovasi berbasis keluasan-daya-jangkau menyebar jauh lebih cepat dan lebih luas dari sebelumnya (Schwab, 2019) Pada era ini sejumlah disnupsi, -khususnya di dunia bisnis telah terjadi. Kasali (2017) menjelaskan dalam tabel berikut sejumlah pola disupsi yang memasuki dunia industry/bisnis pada peradaban yang dikenal dengan peradaban Uber.

Tabel 1 Model Peradaban Uber

\begin{tabular}{|l|l|}
\hline \multicolumn{1}{|c|}{ DUNIA LAMA } & \multicolumn{1}{c|}{ DUNIA BARU } \\
\hline Time series \& linear & $\begin{array}{l}\text { Real time } \& \\
\text { eksponensial }\end{array}$ \\
\hline $\begin{array}{l}\text { Owning Ec onomy } \\
\text { (ekonomi memiliki, } \\
\text { mengua sai, } \\
\text { integra se }\end{array}$ & $\begin{array}{l}\text { Sha ring } \\
\text { Economy } \\
\text { (ekonomi } \\
\text { berbagi, a kses) }\end{array}$ \\
\hline
\end{tabular}

\begin{tabular}{|l|l|}
\hline $\begin{array}{l}\text { On the Lane } \\
\text { Economy } \\
\text { (menunggu pada } \\
\text { antrean) }\end{array}$ & $\begin{array}{l}\text { On Demand } \\
\text { Economy } \\
\text { (begitu } \\
\text { diinginkan, saat } \\
\text { itu juga tersedia) }\end{array}$ \\
\hline $\begin{array}{l}\text { Supply-demand } \\
\text { tunggal }\end{array}$ & $\begin{array}{l}\text { Supply-demand } \\
\text { dengan jejaring }\end{array}$ \\
\hline Lawannya jelas & $\begin{array}{l}\text { Lawan- } \\
\text { lawannya tidak } \\
\text { terlihat }\end{array}$ \\
\hline
\end{tabular}

Sumber: Ka sali 2017

\section{Berbasis}

pemahaman terhadap tabel dimuka, maka kreativitas dan inovasi menjadi hal yang tidak terelakkan dalam pengembangan usaha/bisnisi di masa depan. Inovasi, merupakan kelanjutan dari katan penemuan (invention) dan kegiatan inovasi merupakan penciptaan nilai yang melibatkan peningkatan teknologi. Dalam penciptaan nilai tersebut, inovasi harus secara signifikan mampu memberikan nilai tambah kesejahteraan, yang direpresentasikan pada layak jual (diterima pasar) atau tidaknya produk/jasa inovatif tersebut (Nasution \& Kartajaya, 2018)

UMKM adalah unit usaha produktif yang berdin sendin, yang biasa dilakukan oleh perseorangan atau badan usaha di semua sektor ekonomi. Dalam perekonomian Indonesia UMKM merupakan kelompok usaha yang memiliki jumlah paling besar dan terbukti tahan terhadap berbagai macam guncangan krisis ekonomi (Bukit, Geby, Ivan, \& Fahmi, 2019). Menurut Tarute \& Gatautis, UMKM berperan penting dalam pembangunan ekonomi, pengurangan kemiskinan, dan pembukaan lapangan keja di negara berkembang (Bukit et al., 2019). Secara umum, UMKM memiliki sasaran atau tujuan 
yang ingin dicapai yaitu terwujudnya Usa ha Mikro, Kecil, dan Menengah (UMKM) yang tangguh dan mandiri yang memiliki daya saing tinggi dan berperan utama dalam produksi dan distribusi kebutuhan pokok, bahan baku, serta dalam pemodalan untuk menghadapi persainga $n$ bebas.

Kewirausahaan secara umum adalah keberanian melakukan hal yang kreatif dan inovatif untuk menghasilkan nilai, dan sejumlah penghasilan untuk menghasilkan kemandirian ekonomi dan kema slahatan sosial. Kewirausahaan "lokal berbasis potensi dan masalah di daerah", adalah bentuk potensi dan kekayaan lain dari kewirausahaan khas Indonesia (Wibowo \& Nulhaqim, 2015). Seringkali praktik kewirausahaan menggambarkan bahwa kewirausahaan hanya dapat dijalani dan dimiliki warga kota. Padahal di sisi lain, banyak contoh praktik kewirausahaan yang dilakukan oleh warga pedesaan. Salah satu contoh praktik kewirausahaan di pedesaan yang dilakukan oleh masyarakat desa Cibodas ya itu, "GUESIN PACS".

Desa Cibodas menupakan desa yang terletak di Kecamatan Solokan Jeruk Kabupaten Majalaya Provinsi J awa Barat di mana desa ini memiliki banyak potensipotensi kewirausahaan yang dapat dikembangkan. Salah satu komoditas yang dapat ditonjolkan di Desa Cibodas salah satunya ialah telur asin. Pengusaha telur asin 'Melati' di Deda Cibodas sudah cukup berkembang dan dipasarkan ke penjuru Jawa Barat. Telur asin ini dapat dikembangkan menjadi berbagai produk olahan, salah satunya produk keripik pangsit dengan bahan utama telur asin dan terigu. Produk ini dinamakan "GUESIN PACS", yang diinisiasi oleh Teh Mela Puspitasari, yang merupakan putri dari seorang petemak bebek yang memproduksi telur a sin 'Melati'.

"GUESIN PACS" diproduksi Teh Mela bersama KWT RAPEKAN (Kelompok Wanita Tani). Produk Guesin berbentuk keripik yang dikemas dalam kemasan plastik ziplock dan memiliki lima varian rasa yaitu, original, daun jeruk, cabai rawit, kencur, dan bawang.

Produk Guesin ini mulai dinintis pada bulan November 2019. Pembuatan uji coba Produk Guesin dilakukan pada lima bulan sebelumnya dan mulai berani memasarkan produk pada November 2019.

Dalam pengembangan UMKM di tengah arus globalisasi dan tingginya persaingan membuat UMKM harus mampu menghadapi tantangan global, seperti meningkatkan inovasi produk dan jasa, pengembangan sumber daya manusia dan teknologi, serta perluasan area pemasaran. Hal ini sangat perlu dilakukan untuk menambah nilai jual UMKM itu sendiri, utamanya agar dapat bersaing dengan produk lainnya yang membanjin sentra ind ustri Indonesia.

Penggunaan Sistem Informasi (SI) dan Teknologi Informasi (T) oleh UMKM merupakan suatu hal yang perlu dipelajari oleh para pelaku UMKM. Dimana sistem tersebut berperan sebagai penggerak pembangunan dalam pertumbuhan berkelanjutan suatu bisnis. Pada era digital ini, sistem informasi yang secara luas banyak digunakan adalah intemet. Intemet menyediakan platform teknologi universal baru di mana kita dapat membangun semua jenis produk baru, pelayanan, strategis, dan organisasi. Intemet juga mengubah cara-cara Sistem Informasi digunakan dalam bisnis dan kehidupan sehari-hari (Bukit et al., 2019).

Saat ini produk "GUESIN PACS" dipasarkan dengan metode yang dilakukan secara door to door, sebab masih dalam proses pengenalan kepada masyarakat. Dengan harga yang terbilang cukup tinggi, produk "GUESIN PACS" ini memang ditargetkan untuk masyarakat menengah ke atas.

Konsep Marketing Masa depan menurut Kotler, Kartajaya \& Setiawan (2010) seperti terungkap pada tabel berikut ini: 
Tabel 1.2

Marketing Masa Depan

\begin{tabular}{|l|l|l|}
\hline \multicolumn{1}{|c|}{ Disiplin IImu Marketing } & \multicolumn{1}{|c|}{$\begin{array}{c}\text { Konsep Marketing } \\
\text { Masa Kini }\end{array}$} & $\begin{array}{c}\text { Konsep Marketing Masa } \\
\text { Depan }\end{array}$ \\
\hline Manajemen Produk & $\begin{array}{l}\text { 4P (product, price, } \\
\text { place, promotion) }\end{array}$ & Co-creation \\
\hline Manajemen Pelanggan & $\begin{array}{l}\text { STP (segmentation, } \\
\text { targeting \& positioning) }\end{array}$ & Communication \\
\hline Manajemen Merek & Pembentukan Merek & Character Building \\
\hline
\end{tabular}

(Sumber: Kotler, Kartajaya, Setiawan, 2010)

Kartajaya (2012 dalam Mussry dkk) menjelaskan bahwa elemen pemasaran terdiri dari: Strategy yang terdiri dari segmentation, targeting dan positioning, lalu Tactic terdiri dari differentiation, marketing-mix dan selling, dan ditutup oleh Value yang teidir dari brand, service dan process. Melalui skema ini, maka dapat dibangun sebuah bangunan pemasaran yang kuat dan solid bagi pengembangan usaha. Manajemen pemasaran menurut Kotler (dalam Zainal, dkk 2017) adalah kegiatan penganalisisan, perencanaan, dan pengawasan program-program yang bertujuan menimbulkan pertukaran dengan pasaryang dituju untuk mencapai tujuan perusahaan. Maknanya , membangun sebuah strategi pemasaran, adalah bukan hal yang mudah. Pada konteks era revolusi industry yang sedang berlangsung, maka diperlukan sebuah pendekatan yang mampu menyesuaikan diri dengan zaman. Bagi UMKM, hal ini merupakan tantangan yang besar untuk dapat menyesuaikan diri dengan tuntutan zaman.
Noor, Wibowo dan Zainuddin (2016) merekomendasikan bahwa masih diperlukan proses pemberdayaan bagi pelaku UMKM, yang meliputi kegiatan pemungkinan, penguata $n$, perlindunga $n$, penyokongan serta pemeliharaan. Maknanya, setiap upaya penguatan UMKM merupakan investasi yang berharga untuk mempertahankan dan mengembangkan usaha mereka.

Mauborgne dan Kim (2005) menyatakan dalam strategi mereka "Blue Ocean Strategy" bahwa sebuah usaha bisnis perlu keluar dari lautan merah yang berdarah, dan masuk ke dalam lautan bin yang masih sedikit kompetitomya. Pada konteks UMKM, persaingan di luar jalur daring cenderung sudah sangat padat. Oleh karena itu, membuka kesempatan pelaku UMKM pada jalur pemasaran daring (online) dapat dikatakan sebagai sebuah strategi yang berpotensi meningkatkan tingkat penjualan dan profit mereka.

DIGITALISASI DENGAN ADANYA INTERNET

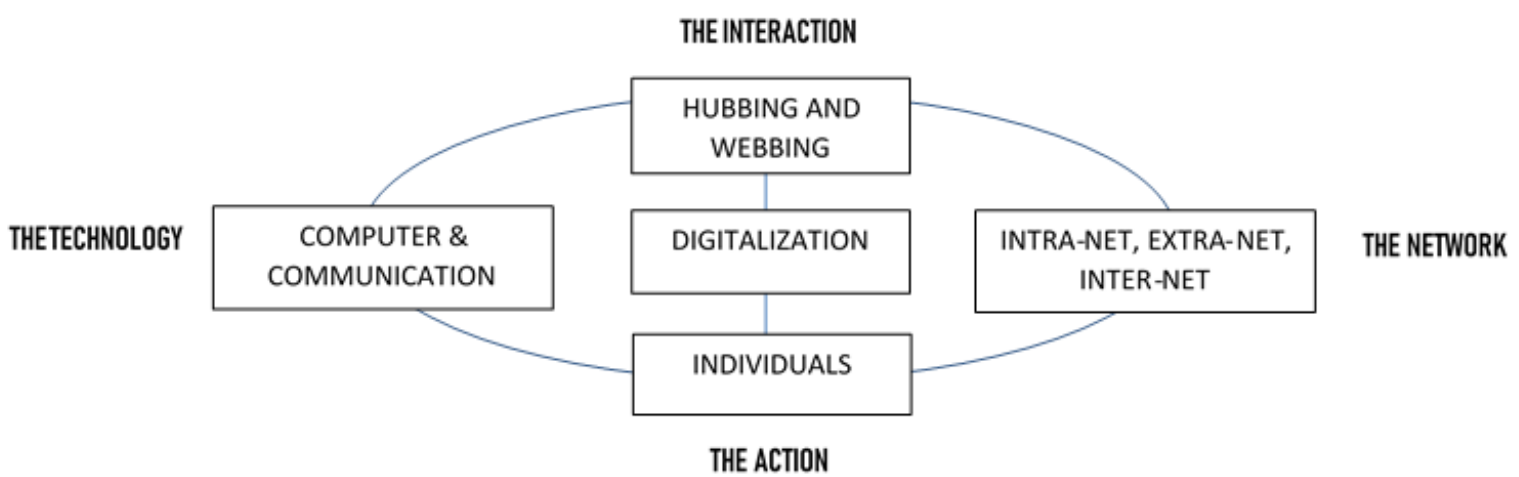


Hadimya pemasa ran daring (online) telah membuat sejumlah perubahan besar pada pasar konsumen dan industry. Kasali (2018) menjelaskannya sebagai berikut: (1) Tingkat persaingan menjadi lebih besar dan rumit dari biasanya, (2) Market penetration, perusahan besar akan mengalami kemunduran, karena pasar akan diisi pendin-pendin baru, (3) akan muncul low-end dan new market yang belum dilayani pemain lama, dan (4) akan muncul metode-metode baru yang akan lebih menyulitkan bagi para pelaku ekonomi lama. Sehingga dalam hal ini, ecommerce atau bejualan online adalah pilihan yang bejualan yang mudah dan murah.

Gambar dimuka menggambarkan bahwa seining dengan menglobalnya pasar, maka proses digitalisasi menjadi sebuah keniscayaan. Atau dengan kata lain, setiap pelaku usaha perlu mempertimbangkan untuk mendigitalisasi pemasaran produk/jasanya, atau mereka akan kesulitan dalam mengembangkan usahanya

\section{METODE}

Aktivitas pengabdian masyarakat ini, secara umum menggunakan penelitian tindakan (action research). Proses di lapangan dilakukan, ya itu di Desa Cibodas, dilakukan dengan upaya keras untuk menghasilkan kegiatan yang berbasis situasi dan kondisi lokal. Penelitian tindakan adalah memiliki keminipan dengan penelitian campuran, namun demikian penelitian tindakan menggunakan metode pengumpulan data yang dapat dilakukan secara kualitatif maupun kuantitatif, tetapi selalu diarahkan pada isu yang bersifat spesifik dan praktis, serta berusaha mencar solusi terhadap pemasalahan yang dihadapi (Yaumi \& Damopoli, 2014). Pada kasus ini, tim pengabdian tejun langsung ke masyarakat untuk melakukan kajian awal kepada pelaku usaha yang ada di Desa Cibodas, yang memang memiliki sejumlah UMKM yang berbasis masyarakat. Tujuan dasar penelitian tindakan lebih ditujukan untuk meningkatkan praktik ketimbang memproduksi pengetahuan, berfokus pada praktik sosial, bertujuan untuk meningkatkan keadaan, merupakan proses siklus, diikuti dengan temuan sistematik, merupakan proses reflektif, bersifat partisipatif dan topik atau masalahnya ditentukan oleh peneliti (Yaumi \& Da mopoli, et.al)

Langkah pengumpulan data dilakukan melalui wawancara, dimana tim pengabdian bertemu langsung dengan pelaku usaha, baik pemilikny maupun para pekerjanya.

Langkah yang dilakukan, mengikuti Model Stringer yaitu melihat, memikirkan dan bertindak (Stringer, 2007 dalam Yaomi $\&$ Damopoli, et.al). Sehingga dapat disusun sebuah kerangka sederhana sebagai berikut:

DIAGRAM 1.1

LANGKAH KEGIATAN (olahan peneliti)

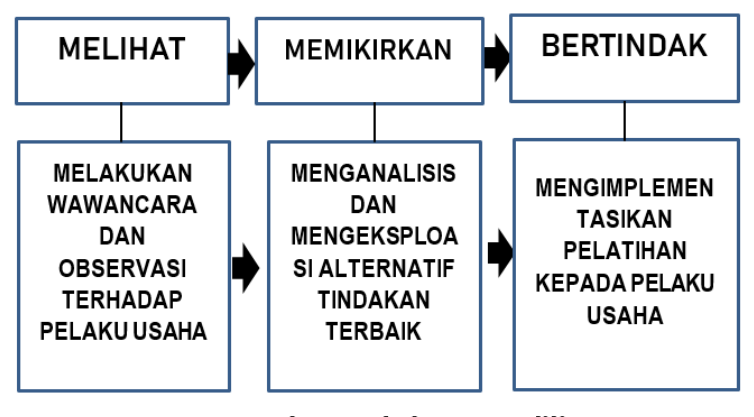

Sumber: Olaha Peneliti

berbasis teori dari Yaumi \& Damopoli, 2014.

Pada langkah awal dilakukan pengumpulan data melalui wawancara pada pelaku usaha dan observasi lokasi usaha mereka. Peneliti berfungsi sebagai instrumen penelitian, dimana peneliti melihat berbagai kemungkinan untuk mengembangkan Teknik yang digunakan sesuai dengan tantangan dan keadaan yang dihadapi dalam proses pengumpulan data (INdrawan \& Yaniawati, 2017). Pada tahapan ini, tim pengabdian terjun langsung ke lokasi pembuatan/produksi dari Guesin Pacs.

Observasi adalah tehnik pengamatan yang sistematis yang diikuti dengan tehnik pencatatan yang sistematis juga untuka membantu perolehan data yang mendasari pemyatan spesifik dari individu atau kelompok yang tercemin melalui perilakunya sehingga nantinya dapat dimaknakan (Kudisyati \& Fahmi, 2019). Observasi dilakukan dengen mencemati lokasi usaha, mendalami tahapan produkis, mengkaji bahwa baku 
yang digunakan dan lain-lain, agar dapat menghasilkan sebuah deskripsi umum yang tajam tejadi kondisi usaha UMKM di Desa Cibodas ini. Kemudian dilakukan Analisa dan terhadap data tersebut dan diputuskan tindakan sela njutnya.

Metode yang digunakan selanjutnya adalah pelatihan. Pelatihan adalah peningkatan pengetahuan, keterampilan dan kemampuan melalui proses pengembangan yang professional (Lall \& Shama, 2009). Selanjutnya, untuk memberikan pemahaman yang baik pada pelaku usaha, dilakukan proses pendampingan usaha.

\section{HASILDAN PEMBAHASAN}

Berdasarkan penelitian yang telah dilakukan, permasalahan utama yang terdapat pada produk GUESIN PACS yaitu belum mampu memanfaatkan teknologi Sistem Informasi berbasis intemet sebagai media promosi pemasaran produk UMKM. Maka melalui pengabdian masyarakat yang merupakan salah satu tri dhama perguruan tinggi, diadakan kegiatan sosialisasi dan pelatihan dalam bentuk workshop pelatihan penggunaan intemet serta pengelolaan akun media sosial sebagai media pemasaran yang mudah dan luas. Selaras dengan model bisnis navigator yaitu salah satunya model bisnis e-commerce, maka dalam hal ini "GUESIN PACS" perlu meluaskan media pemasaran produknya untuk menjangkau pasar yang lebih luas lagi, ya itu dengan mendaftarkan produk terkait kepada e-commerce yang ada dan diminati banyak orang.

Model bisnis e-commerce sendin yaitu menupakan model bisnis di mana barang dan jasa yang biasanya dijual secara konvensional akan dijual melalui jalur online, sehingga dengan begitu tidak memerlukan biaya pokok yang terkait dengan pengelolaan prasarana kantor cabang. Selain itu terdapat manfaat dalam menggunakan model bisnis ini yaitu mudahnya pencarian barang dan jasa secara online yang dilakukan oleh pelanggan. Di sisi lain pelanggan juga dapat membandingkan harga, menghemat waktu dan biaya perjalanan, dan mendapatkan harga yang lebih murah. Manfaat la in ya itu bagi perusa haan adalah tidak penlunya perantara, gerai pengecer, dan iklan biasa yang tidak fokus pada pelanggan tertentu (Gassman et al., 2016).

Berdasarkan metode wawancara, pelatihan, diskusi, dan pendampingan serta data primer yang didapat, mengindikasikan bahwa konsep pemasaran kewirausahaan yaitu dari pengembangan ide dan inovasi yang target pasamya bukanlah masyarakat sekitar. Cara ini dilakukan agar untuk memberikan apresiasi terhadap apa yang sudah dikerjakan para pelaku usaha dalam membangun desa Cibodas. Pada pelatihan ini juga para pelaku usaha saling berdiskusi mengenai cara pelaku wirausaha membangun desa Cibodas lewat berwirausaha.

Salah satunya produk "Guesin Pacs", produk ini mempunyai andil besar dalam memberdayakan istri tani yang berada di Desa Cibodas. Produk ini mempunyai kualitas yang tinggi sehingga memerlukan pasar yang luas pula. Sesuai dengan tema pelatihan yang diangkat yaitu pemasaran daring, maka solusi dan produk ini adalah meluaskan target pasar dengan pemasaran daring. Target pasar dari produk ini merupakan kalangan menengah yang lebih mementingkan kualitas, rupa dan cita rasa. Oleh karena itu produk dikemas dengan rapi dan kualitas serta rasa menjadi konsentrasi utama. Untuk pemasaran kewirausahaan masih menggunakan metode interaktif $d i$ mana sangat membutuhkan ikatan yang erat dengan konsumen. Untuk menjangkau calon konsumen dan menciptakan konsumen baru, masih menggunakan komunikasi berita dan mulut ke mulut. Pemasaran kewirausahaan dilakukan melalui jaringan kontak personal yang informasinya disebarkan secara informal baik oleh konsumen maupun pelaku wirausaha. Kekuatan pemasaran kewirausahaan dapat ditingkatkan dengan cara merekognisi aspek pemasaran yang salah satunya mengikuti era globalisasi.

Seperti yang diharapkan oleh pelaku wirausaha, pemasaran secara digital dapat diterapkan pada produk "Guesin Pacs" ini. Pemasaran produk secara digital dapat dilakukan baik melalui blog, youtube, maupun E- 
commerce. Berikut merupakan opsi yang dapat diterapkan pada produk "Guesin Pacs" yang dipasarkan secara digital:

- Youtube

- Website

- Shopee

- Tokopedia

- Facebook

- DII

Untuk mewujudkan pemasaran produk secara digital, perlu diketahui beberapa hal, antara lain:

1. Mempersiapkan foto produk yang menarik dan jelas untuk calon konsumen.

2. Membuat website atau blog untuk memasarkan produk

3. Memilih jenis e-commerce yang sesuai untuk memasarkan produk. Dan membuat akun di Ecommerce tersebut

4. Memposting produk dan mencantumkan foto serta memberikan spesifikasi yang jelas tentang produk tersebut.

5. Melakukan promosi secara continue dan memberikan diskon serta promo menarik la innya. Hal ini dilakukan untuk meningkatkan brand image bagi konsumen

6. Memberikan pelayanan terbaik untuk konsumen, melalui komunikasi yang dapat memberikan gambaran yang jelas dalam melakukan prosedur pemesanan, pembayaran dan pengiriman produk serta kesesuaian barang yang dipesan dengan katalog

Berbisnis dengan partner bisnis, dan selektif dalam memilih partner bisnis. Hal ini dilakukan agar produk yang sampai ke konsumen tetap terjaga kualitasnya.

\section{PENUTUP}

Pelatihan merupakan sebuah cara yang dapat melatih para pesertanya menjadi mempunyai pengalaman atas tema yang diangkat. Dengan adanya pelatihan kewirausahaan mengenai pemasaran daring di Desa Cibodas dapat mengedukasi para pelaku UMKM dalam memperluas target pasamya. Salah satunya produk "Guesin Pacs" yang telah dibahas sebelumnya mempunyai kualitas yang tinggi sehingga memerlukan pasar yang luas dalam penjualannya. Dengan memberikan motivasi dan mengubah cara pandang dengan 4 cara pendekatan yang berupa sosialisasi, pelatihan, diskusi, dan pendampingan.

Dengan hal ini dapat disimpulkan bahwa para pelaku UMKM sangat terbantu dalam pengetahuan mengenai pemasaran daring. Dengan cara mengenalkan e-commerce pada para UMKM salah satunya pemilik produk "Guesin Pacs" dapat meluaskan target pasar.

\section{KAJ IAN PUSTAKA}

Bukit, F. R. A., Geby, G., Invan, \& Fahmi. (2019). Pembuatan Website katalog Produk UMKM untuk Pengembangan Pemasaran dan Promosi Produk Kuliner. Jumal Pengabdian Dan Pemberdayaan Masyarakat VOL 3 NOMOR 2 SEPTEMBER 2019 JPPM (J umal Pengabdian dan Pemberdayaan Masyarakat)

Gassman, O., Frankenberger, K., \& C sik, M. (2016). Business Model Navigator: 55 Model Bisnis Unggulan yang Akan Mengubah Bisnis Anda. Jakarta: PT Elex Media Komputindo.

Munir, R. (2011). Manajemen Apresia tif: Melejitkan Potensi Dir dalam Karier dan Bisnis Melalui Sikap Menghargai. Bandung: Penerbit Ka ifa PT Mizan Pustaka.

Wibowo, H., \& Nulhaqim, S. A. (2015). Kewirausahaan Sosial: Merevolusi Pola Pikir dan Menginisiasi Mitra Pembangunan Kontemporer. Bandung: Unpad Press.

Haqqi, Halifa \& Wiyanti, Hasna. 2019.

Revolusi Industri $\mathbf{4 . 0}$ ditengah Society 5.0. Cetakan Pertama. Yogyakarta. Penerbit Quadrant.

Noor, Deiki L; Wibowo, Hery \& Zainudd in, Muhamad. 2016. Pemberdayaan UMKM. Jatinangor-Sumedang. Penerbit Unpad Press.

Kasa li, Renald. 2017. Disnupsi. Cetakan 
Pertama. Jakarta. Penerbit PT Gramedia Pustaka Utama

Ka sali, Renald. 2012. Cracking

Entreprenuers. Jakarta. Penerbit PT

Gramedia Pustaka Utama

Kotler, Phlips; Kartajaya Hemawan \&

Setiawan Iwan. 2010. Marketing 3.0:

Mulai dari Produk ke Pelanggan ke

Human Spinit Jakarta. Penerbit Erlangga

Nasution, Aman Hakim \& Ka rtajaya

Hermawan. $2018 . \quad$ Inovasi.

Yogyakarta. Penerbit Andi

Mussry, Iwan; Setiawan, Iwan; Darwin,

Waizly \& Alfisyahr, Rizal. Konsep

Pemikiran Henwamawan Kartajaya:

Dari Indonesia untuk Dunia:

Redefinisi, Simplifikasi dan Futurisasi.

J a karta. Penerbit Erlangga

Ka rtajaya, Hemawan. 2015. Indonesia

Wow, Markplus Wow, We Are Wow.

Cetakan pertama.J akarta. Penerbit PTGramedia Pustaka Utama.

Kasali, Renald. 2018. The G reat Shifting.

Cetakan ketiga. Jakarta. Gramedia Pustaka Utama

Zainal, Veitzal Rivai; Dja ela ni, Firda us;

Basalamah, Salim; Yusran, Husna

Laila; Veithzal, Andria Permata.

2017. Islamic Marketing

Management. Cetakan Pertama. J akarta. Penerbit Bumi Aksara.

Yaumi, Muhammad \& Damopoli, Muljono.

2014. Action Research: Teori, Model dan Aplikasi. Penerbit Kencana Prenada Media Group.

Kusd iyati, Sulisworo \& Fahmi, Irfan. 2019.

Obsenasi Psikologi. Cetakan

Keempat. Bandung. Penerbit PT Rosdakarya

Lall, Mahdurima \& Sha ma, Sheetal. 2009.

Personal Growth \& Training \& Development. New Delhi. Excel Books.

Indrawan, Rully \& Yaniawati, Poppy. 2017. Metodologi Penelitian: Kuantitatif, Kualitatif dan Campuran untuk Manajemen, Pembangunan dan Pendidikan. Cetakan ketiga. Bandung. Penerbit Refika Aditama 